\title{
THE ESSENCE AND GENERAL CHARACTERISTICS OF THE LEGAL POSITION OF THE SUBJECT OF CRIMINAL PROCEDURAL EVIDENCE
}

\section{Klyuev O. M.}

\section{INTRODUCTION}

Proof, like any volitional act of human behavior, combines external (objective) and internal (subjective) properties. The outer side forms its objective side, and the inner side forms its subjective side. Today, criminal procedural science in General and the theory of proof, in particular, unfortunately, do not pay due attention to many subjective moments, do not recognize the proper role played by the category of "personality" in criminal procedural proof. This is explained by the fact that the study of subjective principles is traditionally the subject of the study of General and legal psychology, legal logic and criminology. However, the "dispersion" of the external and internal of the same concept in different branches seems illogical, erroneous, because it affects the completeness of its research. This is the reason for the need to study the subjective side of criminal procedural evidence.

The subjective side of any legal category is its internal component, these are the mental processes that take place in the consciousness of a person and reflect the attitude of her consciousness and will to a certain type of activity that she carries out, and to its consequences. These mental processes (in one form or another and measure) are always manifested in the external world. Moreover, they are decisive in the knowledge of certain phenomena and processes.

The subjective side of the proof of a certain subject is formed by mental processes (which for cognitive purposes can be divided into intellectual and volitional) occurring in the consciousness and will of the subject of proof, and which in their totality Express his personal attitude to the evidentiary activity, it's possible or real consequences. It is obvious that it is not possible to legislatively describe the totality of processes occurring in the consciousvolitional sphere of the subject of proof. That is why science should select (and in the future, probably, and fix in the law) separate, the most significant, typical processes which dominate in consciousness of the subject of proof, and define its relation to criminal procedural evidentiary activity. Among such processes (characteristic features) of the subjective side of 
criminal procedural evidence, we believe, should include the legal position (as the main feature), motive and purpose.

\section{The concept, signs and types of the legal position of the subject of proof.}

In scientific publications, the term "legal position" is quite common, primarily in the context of the constitutional Court of Ukraine $^{1}$. V. Stepankov carried out the study of the essence of the legal position in the General theoretical context of the monographic level. However, in criminal procedural science, the study of this phenomenon, unfortunately, has not received proper development, although, in our opinion, it reflects the essence of the situation, which directly affects the mental processes occurring in the consciousness of the subject of Criminal procedural evidence. Moreover, even in dictionaries and encyclopedias of legal profile interpretation of this term in criminal proceedings. That is, criminal procedural proof can be considered only consciously-volitional behavior of the subject of proof. Thus, all components of the unconscious mental activity of the person are outside the framework of the doctrine of proof, in particular, such an element of its content as the subjective side.

Dictionary offers only understanding of the term "Position": 1) location, location, location, role, place anyone in public life, science, etc. (for Example, a complicated protection position; best position of attorney example V.); 2) view on a particular issue, point of view, the attitude that determines the nature of the actions, behaviors (for example, the lawyer defended his position, the tough stance of the prosecution, the rightful, fair position of the court - an example of Vladimir) ${ }^{2}$.

The Ukrainian legislator does not pay due attention to the legal position of the subject of proof, although it should be noted that this category has already been introduced into the criminal procedural legislation. Thus, in accordance with part 1 of article 22 of the code of criminal procedure "the criminal proceedings is adversarial, providing independent advocacy by the prosecution and by the defense of their legal positions, rights, freedoms and legitimate interests by the means provided in this Code," According to section 6 of article $368 \mathrm{CPC}$ "the court has the right to deviate from the legal position stated in the conclusions of the Supreme Court of Ukraine, with the simultaneous guidance of the relevant motives". However, it is worth noting

${ }^{1}$ Slinko T. Legal positions of the Constitutional Court of Ukraine on the activities of courts of General jurisdiction. Problems of legality. 2011. No. 117. P. 3-13.

${ }^{2}$ Danilyuk I. Modern dictionary of foreign words for secondary and higher schools. Donetsk: LLC PKF “BAO”, 2008. P. 383. 
that so far there are no more references to this term in the current CPC; in other articles, only the term "position" is used to denote the legal position (see, in particular: part 2 of article 292, part 3 of article 349, part 2 of article 364, part 1 of article 419, part 1 of article 442 of the CPC).

As we can see, the concept of "legal position" has entered into legal circulation, but its official interpretation is not contained in the legislation or reference publications. Given the above lexical understanding of the term "position", as well as expressed in the legal scientific literature opinions on the concept of "legal position", without resorting to their critical analysis, we can offer this definition in General theoretical aspect: "legal position" - a system of views, judgments, expressing the attitude of the subject to legal phenomena and processes. Legal positions in the above sense in the legal literature are divided into doctrinal, law-making and law-enforcement.

Doctrinal legal positions is an element of professional legal consciousness, which expresses the idea of law and legal phenomena, which are formed on the basis of philosophical worldview, special legal knowledge and legal practice (an example of such a legal position, views, judgments of scientists, for example, we proposed a vision of the complex-system concept of criminal procedural evidence).

Law-making legal positions are systems of views of subjects of lawmaking on a way and the maintenance of normative regulation of legal relations (for example, a legal position of the legislator concerning the concept, architectonics and the maintenance of the certain bill).

Law enforcement legal positions are official or unofficial opinions, judgments about the legality, validity and fairness of the implementation of legal norms (their kind are the positions of the subjects of criminal proceedings during criminal proceedings). As part of our research, we are interested in this particular kind of legal position.

As already noted, in criminal procedural practice, the term "legal position" became well known and quite actively used. However, despite the seemingly external simplicity of understanding the legal position, in the domestic science of criminal procedure, there is no study at the proper level of this concept at all. To understand the place and essence of the legal position in criminal proceedings and to propose its definition, in our opinion, it is advisable to highlight the essential features of this category ${ }^{3}$.

The emergence of categories (the formation of categorical concepts) or the transformation of a concept into a category is the next step in the scientific knowledge of the essence of a phenomenon. Despite the lack of

${ }^{3}$ Tsalin S. Logical dictionary-reference book / S. Tsalin. Kharkiv: Fact, 2006. P. 135, 253-255). 
developments in the science of criminal procedure, we believe that the epistemological status and level of scientific abstraction "legal position" is precisely the category. Such a vision of the solution of this issue is dictated by General theoretical scientific developments and criminal procedural practice, which, in turn, requires adjustment of conceptual and categorical series of criminal procedural law in General and evidentiary law in particular.

First. Understanding of the legal position as a certain set of mental processes that characterize the attitude of the subject of proof to significant legal facts that relate to the circumstances of the committed criminal offense, in controversial criminal procedural vidnosin 1 . Such a mental attitude is by its nature conscious (because, as already noted, only the conscious-volitional behavior of the subject is a proof) and systematic (that is, such that it consists of separate interrelated considerations).

Second. The legal position of any subject of proof is always conditioned by a certain motive and purpose and is formed on the appropriate evidentiary basis.

Third. The specificity of criminal proceedings implies the need to understand the essence of the legal position not only as a certain mental attitude to evidence, but also the introduction of certain evaluative elements of its content. Indeed, the vision of the legal position only as a mental attitude of the subject of proof there is no procedural significance without its Declaration (public expression, demonstration) and its corresponding assessment by himself and other subjects of proof. It is this understanding of the essence of the legal position can be found in the legislation (in those few cases when the law mentions this term, in particular, in part 1 of article 22 of the criminal procedure code) and practice.

Fourth. The expression of a legal position is an act of conviction in one's own rightness, the truth of one's own conclusions. The subject may have a certain point of view, but he may not always adhere to it. Only when he is sure that his opinion is correct (and this can take place only if there is additional reasoning and, perhaps, practical approbation), it is possible to talk about the emergence of a formed legal position and the beginning of its implementation. Therefore, the legal position is not a simple form of perception of the world-as a thought or point of view, but a complex of mental conclusions, which is characterized by a high degree of stability. In addition, the subject must seek to convince others of the truth of his legal position.

The legal position of the subject criminal procedure evidence (as synonymous, we believe, could be used "the procedural position" or "evidence-based position") - this is due to a certain motive and purpose, formed on the evidence-based conscious belief in the truth of his 
understanding of certain facts of the particular criminal, the justice who publicly expressed (shown) in the form of a private legal evaluation, and assessment of other subjects of proof and has an earnest desire to convince the other.

Based on our proposed definition of the concept of "legal position", we emphasize another aspect of understanding this category. The legal position is not a simple mechanical sum of beliefs, views, opinions, legal feelings, emotions, moods, etc., but a synthesized holistic education, not devoid of its quantitative and qualitative parameters, numerous external contacts and interactions (which, in turn, gives us the opportunity to identify certain types of legal positions of the subjects of proof with simultaneous analysis of the problems of their formation and implementation).

The legal positions of the subjects of evidence in criminal proceedings can be classified:

- by subject-the legal position of the accused, the defender, the Prosecutor, the victim; if the subjects of one party occupy the same, agreed position, the legal position of the defense or the prosecution;

- depending on the legal authority or binding - official (court decision) and unofficial (position of the judge, set out, for example, in his scientific article);

- depending on the method of registration-documented (the indictment of the investigator, approved by the Prosecutor, the verdict of the court) and not documented (the comment of his position by the defender of the accused in a private conversation, in the media or in social networks);

- the degree of relationship with the moral attitudes of society

- moral and immoral;

- on character of interaction of legal positions of various subjects: (a) conflict-free when beliefs of one subject of proof coincide with beliefs of another. Its variety is a conformist legal position, when several subjects agreed their views and came to the same conviction in certain facts; (b) conflict, when the beliefs of one subject of proof contradict the beliefs of others;

- depending on the nature of the external manifestation-passive and active. Passive forms of manifestation of the legal position take place when the subject of proof is contained (evades) from the Commission of normative established or permitted (permissible) actions. The passivity of this type of legal position does not indicate the absence of a goal and motive (the subject of proof believes that he will be able to achieve his goal and satisfy his interests in this passive way, that is, there is a meaningful lack of active actions, a certain reaction). The active form of the legal position of the subject of proof is manifested in the active implementation of certain actions 
(for example, when applying for petitions, complaints, challenges, etc.). Depending on the degree of its external manifestation, it is possible to distinguish such varieties as expressive and impulsive (the latter occurs as a response to a particular situation, sometimes short-term, instantaneous);

- depending on the method of external objectification (bringing to the addressees): (a) verbal, in which the subject of evidence States its position orally (when giving testimony, filing statements, filing petitions, filing complaints, speaking in court debates or with the last word, etc..); (b) textual, when the legal position of the subject of evidence can be expressed in writing (in the indictment, sentence, etc.); (c) visual-aspects, which means a Commission of a subject of proving any demonstrative actions (movements, gestures, adherence to a particular behavior) that allow the addressees of the legal position to see her (nastavena at a time when the court comes to the courtroom when giving evidence during the trial or sentencing court.

\section{The content of the legal position of the subject of proof}

Based on the above mentioned considerations about the nature of the legal position as the primary feature of the subjective side of the criminal procedural evidence and practice of criminal proceedings defined by the subjects of proving that in the implementation process to defend its legal position, we believe that it is possible to allocate the following elements of the content of legal positions: 1) the thesis evidence; 2) evidence-based basis; 3 ) evaluation of self-proving entity and the legal position of the other sub єктів. The content of these elements of the legal position is not static, it can change. Such situation can take place, in particular, in case of change of circumstances of criminal proceedings, volume of the evidentiary basis (in connection, for example, with recognition of separate proofs inadmissible or emergence of new), legal positions of other subjects of proof and so forth.

1. Availability of the thesis of proof. One of the elements of the content of the legal position, in our opinion, is a reasonable (that is, based on a certain evidentiary basis) assumption about the possible and, in the opinion of the subject of proof, the results of Criminal procedural proof are necessary. In the consciousness of the subject of proof, as already noted in the analysis of the subject of proof, may be defined as an educated guess regarding the circumstances of the main facts (events of a criminal offense and a person's guilt in committing criminal offences, the form of guilt, motive and purpose of the Commission (p. p. 1, 2 tbsp. 91 CPC)), and in respect of a number of facts constituting the General thesis of proof. Such assumption in science is called hypothesis (and in criminal process and criminalistics versions). 
2. Evidence-based Foundation. Depending on the version, the existing evidence in the case, subject of proof in the system-the basis of proof of the legal position of the subject. Thus, the evidentiary basis is the systematization of evidence at the discretion of the subject of proof. Its signs are (should be) the logic, integrity, connection of evidence with the disputed legal fact.

Systematization by each subject of proof of the evidence available to him does not exclude the possibility of supplementing, correcting them, which is caused by the course of evidence and factors that affect such a system (in particular, the position of the procedural opponent, the opinion of the court, etc.).

3. Assessment of the subject's own evidence and other subjects of evidence. Legal science treats evaluation in evidence only as an evaluation of evidence. However, there are other objects of evaluation that affect it, but sometimes are not taken into account by the subjects of proof, which leads to inaccuracies and errors. This is similar to when we would estimate the weather solely by temperature: except that it is warm or cold, we would know nothing, because we would exclude such indicators as wind, precipitation, cloud cover, wind direction and speed, and the like.

In the approach to the assessment of evidence from the standpoint of only the assessment of evidence, remain without attention:

- the object of proof (the circumstances in which the evidentiary activity of its subjects);

- the subjective side of the proof of a subject of proof (the thesis of proof, evaluation features (as other substantive elements of the legal position), the purpose and motives of the procedural opponent).

These features of the subjective side cannot be excluded from the assessment, which is carried out by the subject of proof (note that in practice, the assessment of these features, as a rule, is actually carried out);

- specific features of the objective side of criminal procedural evidence (in particular, the time, place, situation and methods of its Commission);

- specific features of certain subjects of evidence that may affect its results.

In addition, it should be noted that evaluation of the subject of proof will be effective not only in accounting for all the components of the content of evidentiary activities of another entity evidence (procedural enemy), but also provided an unbiased and critical attitude to their own evidence (primarily with their own legal positions, in particular, to your goal and interest, which, although not elements of its content, however, determine the legal position of the subject of evidence as well as his thesis of proof (their version) and own evidence base). 
In connection with the above, we believe that in the legislation, scientific and educational procedural literature it will be more correct to use the term not "evaluation of evidence", but "evaluation of evidence".

What is the content of the assessment of evidence? From our point of view, the criteria of belonging, admissibility, sufficiency, significance and reliability are the main ones in the assessment of one's own and "someone else's" procedural evidence, but in another, somewhat broader in comparison with the generally accepted (since it concerns only the assessment of evidence) aspect.

Assessment of evidence means the need to analyze the relationship of the legal position with the circumstances of the committed criminal (or procedural) offense, which are the object of criminal procedural evidence. In addition, from the point of view, this communication will assess all elements of its legal positions (extended version, the evidentiary basis, particularly in assessing one's own evidence and evidence of other subjects), as well as such symptoms subjective evidence of the subject as the objective and the motive that lead to his legal position.

By the way, some of the provisions of the current (and previous) of the act, from our point of view are such, that, in fact, reglamentary requirements affiliation evidence (so, in particular, according to section 6 of article 364 of the $\mathrm{CPC}$, the presiding judge may stop the performance of the participant in the judicial debate, if he comments again gone beyond criminal proceedings, which is carried out, or repeatedly made statements offensive or obscene nature). First, the term "limits of production", we believe, refers not only to the circumstances of the subject of proof, but is a broader concept and may include the points we have mentioned above. Secondly, the content of the speech of the debater is not limited only to the analysis of evidence; it can Express his subjective attitude in the course of criminal proceedings in General, and individual actions and decisions, as well as to the participants in the process, in particular.

Assessment of the admissibility of evidence means the legality of its implementation (i.e. compliance with the legal and social norms governing the procedure for its conduct). When assessing the admissibility of evidence, first of all it is necessary to analyze the main features of the objective side of criminal procedural evidence, which form its content (actions, results and the relationship between them), as well as such features of the objective side of evidence as the place, time, situation, methods and means of its implementation.

Evaluation of the reliability of evidence means the analysis of the results obtained in the process of its implementation from the point of view of their truth. 
The significance of evidence is its value, strength and weight for a particular criminal proceeding. The results of the proof are evaluated for significance first of all, but this does not exclude the possibility of considering them from the point of view of the strength of each of the elements of the legal position of a subject of proof in the process of its implementation. We can talk about the assessment of the claimed thesis of proof, the weight of the evidentiary basis of each subject of proof (the constituent elements of which, incidentally, sometimes may not be used in the results of proof), as well as the importance of the assessment of proof of both their own and other subjects.

Assessment of the sufficiency of evidence means the need to analyze the presence of a set of elements of the legal position of the subject of proof, necessary for making a certain procedural decision (for example, a report of suspicion, carrying out a certain investigative (search) action, a court verdict, etc.).

Based on the above, we can draw this conclusion: assessment of evidence - is a mental (logical) analysis of facilities, affordability, reliability, relevance and sufficiency of the evidentiary activities of all its subjects in specific criminal proceedings.

Summing up given in this part of the reasoning, we emphasize that the authors 'position regarding the assessment of evidence is based on the understanding that, in the practice of criminal proceedings the range of objects procedure legal studies is not limited to evaluation of evidence; evaluation of positions considered (if not, you should consider all elements of proof of criminal procedure (the object, the objective side, all the peculiarities of the subjective side of proof of a specific subject, the subject of proof $)^{4}$.

\section{Assessment of evidence in criminal proceedings}

In the history of criminal proceedings, there are two systems of evidence assessment (in our understanding of evidence assessment): formal and free (based on internal conviction). The formalistic way of knowledge presupposes a certain rule and a clear algorithm of actions and decisionmaking. It has a number of advantages, as it eliminates or minimizes errors, leaves no room for subjective and arbitrary discretion, is more economical. In our times of active technological development in all branches of human activity, there are numerous rules and strict algorithms of action in different

\footnotetext{
${ }^{4}$ Petrusak L. Problem of the origin, development and formation of the rules of evaluation of evidence in criminal proceedings of Russia (historical and legal as - aspects): diss. ... cand. yuri. sciences: spec. 12.00.01. Stavropol: Stavropol. State University, 2000. P. 146.
} 
situations (for example, in traffic, in health care, in construction, in various industries, etc.). And it is quite justified. Every driver, accountant, Builder knows: act according to the rules of the road, according to the laws and regulations governing the accounting and building regulations - and you will always be right ${ }^{5}$.

The formal system of evaluation of evidence (and evidence in General) existed in the medieval detective criminal process. The essence of it is that each proof had a predetermined force and determined in advance their necessary sufficient aggregate. For example, the admission of guilt by the accused was considered perfect evidence-the Queen of evidence for the recognition of the accused guilty was enough testimony of two witnesses; testimony of one witness equated to the testimony of two interested; the testimony of the person occupying the highest class level had an advantage over the testimony of the one who was at the lowest level, etc. This system was based on certain life presumptions (for example, the admission of guilt such a presumption was that the person would not slander himself). However, as practice has shown, such a system was imperfect, unreliable in epistemological terms, led to numerous errors. After all, it can never be ruled out that both disinterested witnesses can give false or false testimony, and each case is unique and inimitable. Therefore, the formal system of evaluation of evidence as an epistemological tool has historically failed and has been replaced by its antipode - free evaluation of evidence.

Despite the fact that in recent years new opportunities have been created to formalize the process of proof at a different, higher quality level, there is no universal algorithm of actions and decision-making suitable for proving in all criminal trials, and, apparently, will never be created. Thus, today the free evaluation of evidence (on internal conviction) is the optimal evaluation system used (and "for lack of better") in the cognitive process in the implementation of criminal proceedings.

Free evaluation is carried out in accordance with certain logical and psychological laws. At the same time, it is regulated by the criminal procedural legislation. According to art. $94 \mathrm{CPC}$ "the investigator, the Prosecutor, the investigating judge, the court on the internal belief which is based on comprehensive, full and impartial research of all circumstances of criminal proceedings, being guided by the law, estimate each proof from the point of view of accessory, admissibility, reliability, and set of the collected proofs from the point of view of sufficiency and interrelation for adoption of the corresponding procedural decision. No evidence has a predetermined force".

${ }^{5}$ Shevchuk I. legal positions of Constitutional Court of Ukraine. Forum rights. 2012. No. 4. P. $1064-1069$. 
First of all, we note that the cited norm of the law should be interpreted broadly. After all, we will repeat, during criminal proceedings on internal beliefs are estimated not only proofs, but also other elements of a legal position of the subject of proof (and also those signs of the subjective party of proof causing a legal position (the purpose and motive)). In addition, as we have already stated above, other substantive elements of criminal procedural proof should be evaluated according to internal conviction: its object, all manifestations of the subjective and objective side of proof and all the features of the subjects who carry it out.

As we can see, the Central, defining element in the system of free evaluation of evidence is the category of internal belief, which, in our opinion, requires special attention in this study.

Inner conviction: urgency and function. Elucidation of the essence of inner belief, its content and mechanism of formation is of great scientific and practical importance. First of all, it is necessary to determine the urgency, in other words, to answer the question whether the term "internal conviction" Meets the requirements of the science of criminal procedure and legislative technology.

The system of free evaluation of evidence in criminal proceedings arose at the end of the XVIII century. And it was no accident, because at the heart of the worldview at that time were different philosophical schools of idealism, which linked the establishment of truth with the consciousness of man. Determinism, a materialist theory of knowledge in the XVIII century only began to be developed and has not gained wide popularity.

Consciousness was understood as a closed inner world, which reflects not the external being, but itself. Because of this, it was proclaimed that internal self-observation should be taken as the basis of any knowledge ${ }^{6}$. Through introspection, a person can study his feelings, thoughts, desires, without resorting to an objective analysis of the causes that cause them, and the mechanism of their formation.

It was in the works of famous philosophers of that time, who were supporters of these methods of research of the objective world, that the term "inner conviction" first appeared, which took its place among such terminology of the introspective school: "inner perception", "inner knowledge", "inner imitation", "inner experience".

The disclosure of the nature of the inner belief, in our opinion, requires the solution of the question of its functional purpose. In the criminal

\footnotetext{
${ }^{6}$ Petrusak L. Problem of the origin, development and formation of the rules of evaluation of evidence in criminal proceedings of Russia (historical and legal as - aspects): diss. ... cand. yuri. sciences: spec. 12.00.01. Stavropol : Stavropol. State University, 2000. P. 146.
} 
procedural literature on this issue expressed various, sometimes quite contradictory opinions. Without resorting to their analysis, we believe that it is possible to support those scientists who consider internal research as a method, as a result, and as a criterion (standard) for evaluating evidence (evidence). Let us consider the peculiarities of this understanding.

Internal persuasion as a method means an approach to the evaluation of evidence, which is characterized by the absence of any formal requirements of the law primarily with regard to the reliability and significance of evidence and evidence in General (although this may apply to other properties of the latter). This approach is based on the legal knowledge and professional experience of the subject of proof, on the knowledge gained in the process of proving certain circumstances of criminal proceedings, on personal moral qualities. As a method of evaluating evidence internal persuasion means meeting the following requirements:

- first - the content of part 1 of article 94 of the CPC is not bound by the subject of the assessment the views of other entities that forbid anyone to interfere in this activity. All subjects who carry out the assessment of evidence (own or other subject) are free in their value judgments, conclusions that they make on the basis of a comprehensive, complete and unbiased study of all the circumstances of criminal proceedings;

- the second - from the contents of part 2 of article 94 of the criminal procedure code-no evidence for the investigator, Prosecutor, investigating judge, court have a predetermined force. This means that criminal procedural rules do not contain prescriptions, what evidence should be determined by certain circumstances, and do not establish in advance the strength of evidence that does not give some of them priority over others.

Consequently, the law guarantees the subject both" external "freedom, whether it protects him from external influence, and "internal", without binding him with any formal requirements regarding the proof of a particular subject. Without these two characteristics, free evaluation (by inner conviction) ceases to be such, turns into its opposite.

Internal belief as a result of the evaluation of evidence can be considered in several aspects (as a rule, traditionally considered in the epistemological, logical and psychological sense ${ }^{7}$ ).

In the epistemological aspect, it is the result of reflection in the consciousness of the subject of proof of the object of research (circumstances of the subject of criminal procedural proof to be established).

${ }^{7}$ Shevchuk I. legal positions of Constitutional Court of Ukraine. Forum rights. 2012. No. 4. P. 1064-1069. 
The logical nature of the internal belief is that it is made on the basis of compliance with the laws and rules of logic categorical and (in the opinion of a certain subject) reliable, meaningful and the only possible conclusion about the circumstances of the subject of proof.

In psychological terms, internal belief is "a certain state of the psyche of the individual, the property of the inner life of his consciousness. It is directly given to man as an act of experience". According to L. Petruchak, the psychological aspect of persuasion should be considered as a product of the interaction of the mind, feelings and will, because it is not just a thought, a correct view, but an emotionally colored inner force that regulates and directs human behavior.

The inner conviction reflects the originality and peculiarities of the mental warehouse of each subject of proof. The functional purpose of the psychological component of the belief is that it helps to overcome doubts arising in the process of knowledge, determines its active creative nature. It is the psychological aspect of internal conviction as a result of the evaluation of evidence is manifested in the requirement of the law on the motivation of the conclusions of a certain subject of criminal proceedings.

Inner conviction is fundamentally different from intuition. It is achieved in the course of objective knowledge of reality, based on comprehensive research and evaluated evidence and their sources. To decide by inner conviction means to realize the only correctness of what is affirmed or denied, to have a reasonable confidence in the truth of one's judgments and the objective material necessary for this ${ }^{8}$.

Some scientists pay attention to the moral and ethical side of internal belief $^{9}$. After all, internal belief as an ethical category is a rational basis for the moral activity of a person, allowing her to perform a particular act consciously, with an understanding of the necessity and expediency of a certain behavior ${ }^{10}$. Ethical elements in judicial persuasion convey the value orientation of the judge, his moral ideals and views. Their functional purpose is that they form the moral basis of conclusions on the merits of the criminal case under consideration.

In General, agreeing with the need to highlight this aspect, we believe that we should support N. Poplavska, who believes that it should be

\footnotetext{
${ }^{8}$ Petrusak L. Problem of the origin, development and formation of the rules of evaluation of evidence in criminal proceedings of Russia (historical and legal as - aspects): diss. ... cand. yuri. sciences: spec. 12.00.01. Stavropol: Stavropol. State University, 2000. P. 146.

${ }^{9}$ Problems of formation of judicial conviction in criminal proceedings: Monogr. Kharkiv: Vishch. SHK. 1975 / in the book. Grosheva Y. Selected works / comp.: Kaplina O., Marinov V. Kharkiv: Pravo, 2011. P. 25.

${ }^{10}$ Moskalkova T. Ethics of criminal procedural proof (stage of preliminary investigation) / T. Moskalkova. Moscow: Spark, 1996. P. 88.
} 
considered within the social nature of internal belief ${ }^{11}$ (in other words, to highlight its social aspect, which includes the moral and ethical side). The social component of internal belief, as a broader concept, in addition to compliance with moral and ethical standards (as a variety of social norms), means that it must meet the goals and objectives of criminal proceedings, due to the interests of society (society) and the corresponding legal ideology that prevails in it.

Based on the analysis of the content of article 94 of the criminal procedure code, in our opinion, it is also necessary to highlight the legal aspect of internal conviction as a result of the evaluation of evidence. This side of the concept under consideration is the validity and motivation of the internal conviction to which the subject of proof has reached on the basis of a comprehensive, complete and impartial study of all the circumstances of the criminal proceedings and in the manner prescribed by law.

The content (structure) of the internal belief as a result of the evaluation of evidence. It is also important to focus on the content (structure) of the internal belief as a result of the evaluation of evidence in order to fully clarify the essence of this category, which will help to clarify the essential elements (signs) of the internal belief and formulate its concept. It is advisable to apply primarily to the analysis of scientific works devoted to the study beliefs, because, as noted by Y. Manishev, "conviction" is a General sociological category. This means that all its types (philosophical, political, religious, moral, judicial, etc.) have common features (or signs) that are repetitive and act as elements of belief. It is through the definition of these elements (features, traits) can reveal the contents of the internal beliefs ${ }^{12}$.

Y. Manisheva identified five elements that form the mechanism of any belief: 1) knowledge about the subject matter; 2) attitude to the truth in the sense of ideal forms; 3) a sense of confidence or uncertainty; 4) objective attitude (positive or negative) to the phenomena of the external world; 5) subjective willingness to act ${ }^{13}$. We believe that such an approach can be taken as a basis for determining the elements (signs, traits) of the concept of internal conviction of the subject of criminal procedural evidence.

The first element of the content of conviction is knowledge about the circumstances of the subject of criminal procedural evidence in a particular criminal proceeding. Belief cannot exist without knowledge. However,

${ }^{11}$ Poplavskaya N. Freedom of evaluation of evidence in criminal proceedings of Russia: Monogr. Moscow: Yurlitinform Publishing house, 2009. P. 82-84.

${ }_{12}$ Koblikov A. Legal ethics: studies. Moscow: NORM Publishing house (Ed. gr. NORMA-INFRA M), 2000. P. 68, 69.

${ }^{13}$ Moskalkova T. Ethics of criminal procedural proof (stage of preliminary investigation) / T. Moskalkova. Moscow: Spark, 1996. P. 88. 
knowledge and beliefs are not the same: knowledge may not translate into beliefs, and beliefs may not always be based on clear and complete knowledge. In addition, the concept of "belief" is broader than the concept of "knowledge". Knowledge expresses the relation of the epistemological character to reality, whereas belief is the relation of the subject already to the epistemological image. The latter is possible only through the comparison of knowledge with practice, public interests and goals facing the subject of proof.

This understanding of belief and its relationship with knowledge and meet the above point of view about the need to consider the epistemological essence of criminal procedural evidence from the standpoint of the classical theory of knowledge, and with the use of cognitive science, one of the components of which is epistemology as a science of knowledge.

The second element belief is the relation of the subject of proof to the content of knowledge to the proper, admissible, reliable, significant and sufficient. Certain knowledge, which, for example, does not relate to the circumstances of the subject of proof or obtained in violation of the procedure established by law, is excluded from the further process of forming the conviction of the subject of proof.

Thus, according to L. Petruchak, in the process of judicial proceedings, judges rhyme the necessary and sufficient amount of knowledge, but only a part of them is put into the basis of beliefs. The acquired knowledge goes through a complex process of emotional and intellectual assessment, as a result of which their reliability is established. The conclusion about the reliability of knowledge is the main prerequisite for their transition into a belief that is predetermined by the objectives and goals of justice. If the reliability of knowledge is not established, they cannot serve as a basis for judicial conviction ${ }^{14}$.

Although, as noted above, reliability is not the only factor in the conversion of knowledge to judicial conviction. In the process of evaluation, the determination of their belonging, admissibility, significance and sufficiency is carried out. Therefore, before establishing the reliability of specific knowledge related to the subject of proof, obtained in the manner prescribed by law, have no value or are dealing with already acquired knowledge is not used in the formation of beliefs of the subject of proof.

The third element of the internal conviction of the subject of criminal procedural proof is the mental attitude to the essence of the knowledge

${ }^{14}$ Petrusak L. Problem of the origin, development and formation of the rules of evaluation of evidence in criminal proceedings of Russia (historical and legal as - aspects): diss. ... cand. yuri. sciences: spec. 12.00.01. Stavropol : Stavropol. state University, 2000. P. 146. 
obtained., which is expressed in a sense of confidence in them. Confidence is a state of the subject of proof, when he does not hesitate to express their attitude to the truth results of knowledge. Close to the mental state of confidence is the state of faith; sometimes they are regarded as identical. However, it is worth to support the position of the L. Petrochuk, which believes that between these States there are significant differences. Confidence is characterized by the validity and concreteness of the knowledge that causes it; the state of faith arises with respect to sensually not given objects, not mastered in the process of cognitive and practical activity. For faith is not necessarily the presence of a sufficient amount of evidence supporting the truth of its knowledge ${ }^{15}$.

From the feelings of confidence, it is necessary to distinguish the sense of self-confidence, which can also lead to a conviction. However, sometimes as a result of overestimation of their capabilities and knowledge, unjustified failure to take into account certain factual data of criminal proceedings, selfconfidence can lead to hasty, unfounded conclusions, that is, to a false belief.

The opposite of confidence is doubt. According to the explanatory dictionary of the Ukrainian language, doubt is uncertainty about the probability, the possibility of something; lack of firm confidence in someone, for some reason; complications, misunderstanding that arise when solving any question, a certain problem; a state of mental disorder, uncertainty, hesitation ${ }^{16}$. Doubt cannot lead to the formation of a conviction in the subject of proof. Criminal procedure law explicitly prohibits in case of doubt, i.e. in the absence of inner beliefs, to make decisions about a person's guilt in committing a criminal offence (article 62 of the Constitution of Ukraine, article 17 of the code). At the same time, the feeling of doubt has a positive role in criminal procedural proof. It always arises from the subject of proof, if there is insufficient knowledge about the circumstances of criminal proceedings or if the knowledge obtained is contradictory. Doubts encourage to take measures, commit actions aimed at obtaining new knowledge, which will make it possible to eliminate them and form a reasonable belief.

The fourth element of the content of the belief is the subjective (positive or negative) attitude to the investigated objective phenomena. It is formed in the subject of proof as a result of moral assessment, the essence of which is to compare the actions of the person (the accused, the victim, etc.) with the

15 Petrusak L. Problem of the origin, development and formation of the rules of evaluation of evidence in criminal proceedings of Russia (historical and legal as - aspects): diss. ... cand. yuri. sciences: spec. 12.00.01. Stavropol: Stavropol. state University, 2000. P. 146.

${ }^{16}$ Slinko T. Legal positions of the Constitutional Court of Ukraine on the activities of courts of General jurisdiction. Problems of legality. 2011. No. 117. P. 3-13. 
interests of other people and society as a whole. This comparison takes place on the basis of the prevailing moral norms and values in society. Thus, the actions or behavior of certain persons in criminal proceedings that meet the interests of society, the state, individual citizens (for example, the suspect (accused) gave truthful testimony, appeared on call, etc.) cause a positive attitude. Opposite actions or behavior, on the contrary, generate a negative attitude among the subjects of proof.

The fifth element (which is highlighted by almost all researchers of the essence of the concept of "belief") is the volitional state of the subjects of proof, their willingness to act in accordance with the knowledge that underlies the belief. When the subject lacks the determination to act or make appropriate decisions (for example, the court doubts the conviction), it means that he has not yet formed a conviction. The state of readiness to act on their inner beliefs is an indicator of the strength of confidence of the subject of proof in the truth of their knowledge.

Summing up the stated concerning the content of internal belief, it is worth noting that its first element - knowledge, being the basis, the basis of belief, constitute its objective side. According to V. Bohan, true knowledge, which correctly reflects the objective reality, has a meaning that does not depend on the consciousness of judges. Having knowledge, the subject of proof must reckon with them, he cannot ignore them or change at will. That is why the process of forming a belief and its meaning acquire an objective character. The last four elements of the content of a belief Express its subjective side, which indicates that beliefs are the product of the mental activity of the subject of proof. It depends on his mental capacity, life experience, physiological and mental state, and the like.

Separately, each of the defined and analyzed elements does not cause the subject to prove the belief, its appearance is possible only as a result of their dialectical development and interaction.

In the philosophical literature, the process of forming a belief is described by the formula "recognized-understood - experienced-accepted as truth". As we can see, it lacks the fifth element of conviction-the willingness to act. V. Bohan transfers this formula to the formation of the judicial conviction, adding to it the specified element: "recognized-understoodexperienced-taken for the truth - prepared decision".

Criticizing the given understanding of the mechanism of formation of belief, Y. Grosheva, noted that in such cases the role of the law, professional legal consciousness, the social position of the judge established in trial of set of proofs in the decision-making mechanism is belittled. In his opinion, these formulas separate cognitive elements from psychological and ethical 
ones in the structure of judicial conviction, which always appear in dialectical interrelation and interdependence ${ }^{17}$.

From our point of view, the proposed definition of the formula of the mechanism of formation of the conviction of the subject of criminal procedural evidence is still possible. Moreover, it seems that to determine its components, the above-analyzed elements of the content of belief can be taken as a basis (after all, they take into account the role of the law, professional legal consciousness, and other components named by Y. Groshev), as well as the approaches expressed in philosophy and procedural literature. On the basis of the stated we consider it possible to offer the author's formula of interrelation of elements of the mechanism of formation of internal belief of the subject of criminal procedural proof: "it is identified-analyzed on suitability - truth is determined-subjective attitude is formed-readiness to act is demonstrated".

Having considered the essence of internal belief, its structure and process of formation, we will try to define this concept. Inner conviction of a subject of criminal-procedural evidence (how assessment of evidence) is obtained in the manner prescribed by law, knowledge about the circumstances of the subject of criminal procedure evidence in specific criminal proceedings which, in the opinion of the subject evidence is credible, relevant and sufficient (that is suitable for proof), which is the feeling of certainty concerning the nature of this knowledge is manifested in the subjective (positive or negative) attitude to the study of objective phenomena, and makes a willful willingness to act.

\section{CONCLUSIONS}

1. The legal position of the subject of criminal procedural proof is his conscious conviction in the truth of his understanding of the problems of proof as a whole, and its specific manifestations (elements) in a particular criminal proceeding, in particular, with a clearly expressed desire to convince other persons of this, which is due to a certain motive and goal, formed on a separate evidentiary basis, and publicly expressed (demonstrated) in the form of his own legal assessment and assessment by other subjects of proof.

2. The content of the legal position of the subject of criminal procedure evidence includes: 1) the existence of the thesis of proof; 2) the evidentiary basis; 3 ) the assessment of the subject's own evidence and the legal position of other subjects.

17 Problems of formation of judicial conviction in criminal proceedings: Monogr. Kharkiv: Vishch. SHK., 1975 / in the book. Grosheva Y. Selected works / comp.: Kaplina O., Marinov V. Kharkiv: Pravo, 2011. P. 25. 
3. When describing the assessment as an integral element of the legal position of the subject of proof, it should be not only about the assessment of evidence, but also evidence as a whole. This means that all the constituent elements of the content of the proof must be evaluated: the object, the subjective side, certain features of the objective side of the proof and certain subjects that carry it out. In connection with the stated in the legislation, scientific and educational literature it will be more correct to operate with the concept not "assessment of proofs", and "assessment of proofs".

4. The category of "internal belief" is a Central defining element in the system of free evaluation of evidence. The term "internal" has its own meaning: it defines the mechanism of formation of a change in the subject of proof.

5. The essence of internal belief is that from the point of view of functional purpose, it can be considered as a method, and as a result, and as a criterion for evaluating evidence. As a method of assessment to use of either internal belief has the following essential characteristics: (a) the incompatibility of the subject of the assessment the views of other actors, that is, forbid anyone to interfere in such activities (the so-called "external" freedom (part 1 of article 94 of the CPC); (b) the absence of a predetermined strength of evidence for the investigator, Prosecutor, investigating judge, court (so-called "internal" freedom) (part 2 of article 94 of the CPC).

\section{SUMMARY}

The article discusses the concept, characteristics and types of legal position of the subject of proof, the legal position of the subject criminal procedure proof, the content of the legal position of the subject of proof, the availability of the thesis of proof, evidentiary-based assessment of their own evidence, the subject and other subjects of evidence evaluation of evidence in criminal proceedings

\section{REFERENCES}

1. Problems of formation of judicial conviction in criminal proceedings: Monogr. Kharkiv: Vishch. SHK., 1975 / in the book. Grosheva Y. Selected works / comp.: Kaplina O., Marinov V. Kharkiv: Pravo, 2011. P. 25.

2. Danilyuk I. Modern dictionary of foreign words for secondary and higher schools. Donetsk: LLC PKF "BAO”, 2008. P. 383.

3. Campo V. Legal positions of the constitutional Court of Ukraine as a necessary element of judicial and legal reform. Bulletin of the KSU. 2010. No. 2. P. 112-122.

4. Koblikov A. Legal ethics: studies. Moscow: NORM Publishing house (Ed. gr. NORMA-INFRA M), 2000. P. 68, 69. 
5. Moskalkova T. Ethics of criminal procedural proof (stage of preliminary investigation) / T. Moskalkova. Moscow: Spark, 1996. P. 88.

6. New explanatory dictionary of the Ukrainian language: 200000 words: in 3 vols. [2nd ed., ISPR.] / way.: Yaremenko V., Slipushko O. Kiev: Akonit, 2008. Vol. 2: K-P. P. 757.

7. Novitsky, V., Theory of the Russian procedural evidence and practice: monograph. Stavropol: Publishing house of SSU, 2002. 584 p.

8. Petrusak L. Problem of the origin, development and formation of the rules of evaluation of evidence in criminal proceedings of Russia (historical and legal as - aspects): diss. ... cand. yuri. Sciences: spec. 12.00.01. Stavropol: Stavropol. state University, 2000. P. 146.

9. Poplavskaya N. Freedom of evaluation of evidence in criminal proceedings of Russia: Monogr. Moscow: Yurlitinform Publishing house, 2009. P. 82-84.

10. Slinko T. Legal positions of the Constitutional Court of Ukraine on the activities of courts of General jurisdiction. Problems of legality. 2011. No. 117. P. 3-13.

11. Stepankov V. Legal position: General theoretical and applied aspects: Diss. ... Cand. Yuri. Sciences: spec. 12.00.01. Nizhny Novgorod, 2003. $186 \mathrm{c}$.

12. Teslenko N. Legal force and value of legal positions of the constitutional Court of Ukraine. Bulletin of the KSU. 2003. No. 4. P. 36-41

13. Tkachuk P. Legal positions of the constitutional Court of Ukraine. Bulletin of the KSU. 2006. No. 1. P. 10-21.

14. Tsalin S. Logical dictionary-reference book / S. Tsalin. Kharkiv: Fact, 2006. P. 135, 253-255).

15. Shevchuk I. legal positions of Constitutional Court of Ukraine. Forum rights. 2012. No. 4. P. 1064-1069.

Information about the author: Klyuev O. M., Doctor of Law, Professor, Director of the Kharkiv Scientific Research Institute of Forensic Examinations N.A. Prof. M. S. Bocarius

of the Ministry of Justice of Ukraine 8-A, 49 Zolochivska str., Kharkiv, 61177, Ukraine 